\title{
Iron-deficiency anaemia during the first two years of life
}

\author{
Magnus Domellöf and Olle Hernell
}

Department of Clinical Sciences, Pediatrics, Umeå University, SE-90I 85 Umeå, Sweden

\begin{abstract}
Iron-deficiency anaemia (IDA) is a global public health problem, affecting an estimated $51 \%$ of children below 4 years of age in developing countries and $12 \%$ in developed countries. Owing to rapid body growth and a depletion of neonatal iron stores, iron requirements during late infancy are higher than during any other period of life. There is a well-known association between IDA and delayed neurodevelopment in infants and young children. Early weaning to cow's milk or formula unfortified with iron is known to increase the risk for IDA in this age group. Iron fortification of common infant foods is recommended in many countries. Iron supplements are often recommended for infants who are breast-fed for longer than 4-6 months and who do not consume adequate amounts of iron-fortified complementary foods. The scientific bases for these recommendations are discussed in this review, as are safety aspects, and the diagnostic criteria for IDA in infants and young children are critically examined.
\end{abstract}

Keywords: Human infant, infant nutrition, iron-deficiency anaemia, iron status, iron supplementation, nutritional requirements.

Received: February 12, 2002. Accepted: February 25, 2002

\section{Introduction}

Iron is essential for virtually all living organisms. The quantitatively dominating function of iron in the human body is as the oxygen-binding core of haemoglobin $(\mathrm{Hb})$, the red pigment of blood, transporting oxygen from the lungs to all tissues. During the progress of iron deficiency (ID), $\mathrm{Hb}$ synthesis in the bone marrow is restricted and anaemia (low $\mathrm{Hb}$ in blood) results. Anaemia caused by ID is called iron-deficiency anaemia (IDA), distinguishing this condition from other causes of anaemia, such as infection, inflammation, haematological disorders and other nutritional deficiencies.

IDA is the most common micronutrient deficiency in the world, with about 600 million individuals affected (1). Rapid growth makes infants and young children a particular risk group for IDA. In 1980, the World Health Organization (WHO) estimated the world-wide prevalence of anaemia in children below the age of 4 years to be $43 \%$, with a higher prevalence in developing regions $(51 \%)$ than in developed regions (12\%) (2).

\section{History}

In the early twentieth century, anaemia was prevalent and often severe among infants in the Western world, especially in poor families, and often in combination with general malnutrition and chronic infections, a situation resembling current conditions in many developing countries (3). However, the cause for anaemia in these infants was not known and treatment was controversial. At that time, a vast majority of infants were breast-fed during most of their first year of life, but the use of cow's milk was gaining in popularity (4). It was recognized that anaemia was more common in infants who were fed cow's milk than in those who were not (3). In 1928, the British paediatrician Helen Mackay showed that anaemia in infants could be prevented through iron fortification of evaporated cow's milk (5). Unfortunately, several decades passed before iron fortification of milk or infant formulae came into more widespread use.

In the 1940s, IDA was regarded as the most common anaemia during infancy (3). At that time, most infant formulas were prepared at home from evaporated milk, water and sugar, with or without flour. In the 1950s, the popularity of commercially prepared infant formulae increased dramatically. During the 1950s and 1960s, IDA in infancy was still common, with a prevalence of over $40 \%$ in some urban populations (6). Iron fortification of commercial formula was introduced after the stud- 
ies of Marsh (1959) and Andelman (1966), who essentially confirmed the results of Mackay $(7,8)$. However, the use of unfortified formula and whole cow's milk was still common and breast-feeding continued to decline until about 1970. During the 1970 s and 1980s, the prevalence of IDA among children diminished in developed countries, a decline attributed to the increased use of iron-fortified infant formulae and other iron-fortified infant foods (9). At the same time, there was a marked increase in breast-feeding in the Western world, possibly contributing to the decline in IDA and also leading to new research questions concerning the iron requirements of breast-fed infants (10).

\section{High iron requirements in infancy}

In adult humans, there is little exchange of iron between the body and the environment, since body iron is recycled and physiological iron losses are small. In the infant, however, the recycling yields a deficit since a substantial part of iron turnover is diverted to growing tissues. Figure 1 shows that in an infant aged 6 months, about $0.5 \mathrm{mg} \mathrm{day}^{-1}$ is needed for "blood growth" and $0.1 \mathrm{mg} \mathrm{day}^{-1}$ for growth of muscle and other tissues. Since iron requirements without growth would equal basal iron losses $\left(0.15 \mathrm{mg}\right.$ day $\left.^{-1}\right)$, infant growth increases iron requirements 5-fold to approximately $0.75 \mathrm{mg} \mathrm{day}^{-1}$ (Fig. 1).

As a consequence of reduced $\mathrm{Hb}$ concentration and a redistribution of iron to storage sites, the infant is able to double its birth weight without exhausting iron reserves, independent of external

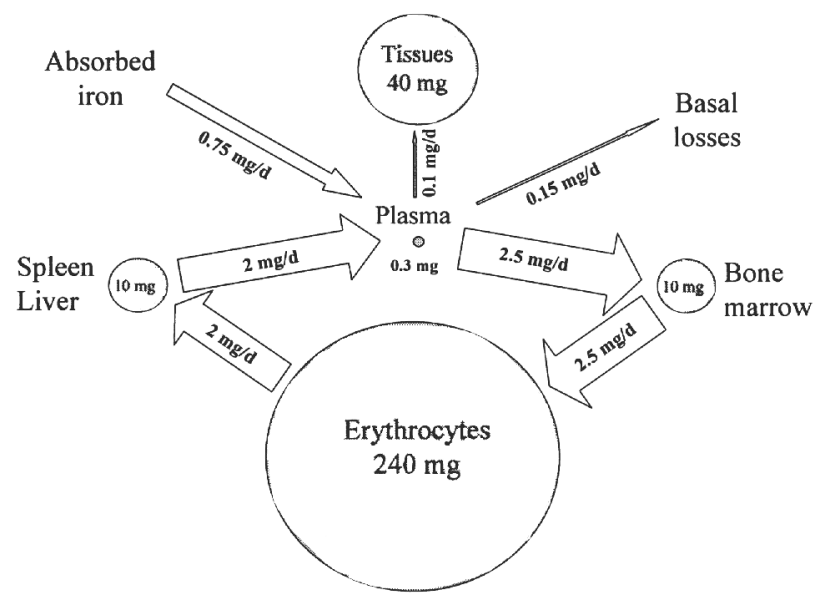

Fig. 1. Approximate iron turnover between major iron compartments at 6 months of age. The width of each arrow is proportional to iron flux; the area of each circle is proportional to compartment size.

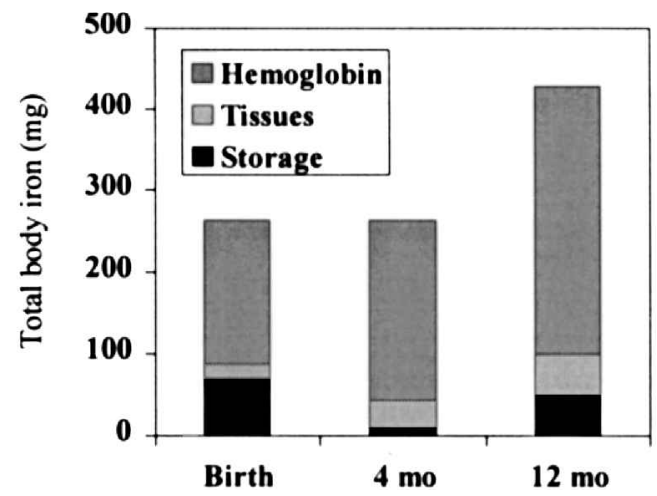

Fig. 2. Changes in body iron during infancy. [Modified from Dallman 1992 (13).]

iron (11). For term infants this occurs at about 5 months of age and, soon thereafter, iron absorption from the diet becomes critical to the maintenance of iron balance (12).

In proportion to body weight, the need for dietary iron is greater during late infancy than during any other period of life (Fig. 2) (13). Based on assumptions about certain factors such as total body iron at birth and basal iron losses, Oski estimated the average requirement for absorbed iron during the first year of life to be $280 \mathrm{mg}$, averaging $0.8 \mathrm{mg} \mathrm{day}{ }^{-1}$ (12). This is an intake which is virtually impossible to achieve with unmodified complementary foods, suggesting that additional iron is needed, either as food fortification or as separate iron supplements, to cover the estimated needs (14).

A randomized trial of iron supplementation of Swedish and Honduran infants of normal birth weight was performed recently (15). These infants were all exclusively breast-fed until 6 months of age but significant differences in iron status between Swedish and Honduran infants were already observed at 4 months of age. At 9 months, when the infants were partially breast-fed, the prevalence of IDA in unsupplemented Swedish infants was < $3 \%$, suggesting that the iron requirements of these infants are lower than previously assumed. However, in Honduras, $28 \%$ of the unsupplemented infants were classified as having IDA at 9 months, suggesting higher iron requirements in a socioeconomically disadvantaged population, possibly partly because of the poor nutritional status of mothers, limiting foetal iron accretion.

\section{Consequences of iron deficiency}

Nutritional IDA rarely causes any overt symptoms in infants and young children. Fatigue and tachyp- 
noea only occur in severe anaemia. Pallor is a consistent finding in cases of moderate and severe anaemia, but often passes unnoticed by the parents.

\section{Neurological impairment}

Many observational studies have shown that young children with IDA have poorer cognitive and motor functions than do controls. These differences have remained when controlling for social background factors, even though the possibility of confounding environmental factors or nutritional deficiencies other than iron cannot be completely excluded (16, 17). Using brainstem auditory evoked response, Roncagliolo et al demonstrated significantly prolonged central conduction time in 6-month-old infants with IDA, possibly suggesting impaired myelination of central nervous system neurons (18). This would be consistent with rat experiments documenting the essential role of iron in myelin formation and brain development $(19,20)$.

Randomized treatment trials as well as prophylactic iron supplementation trials in children aged $<2$ years have yielded conflicting results, some showing a benefit of iron $(21-23)$ and others not $(24,25)$. Several randomized controlled trials in schoolchildren with ID and IDA have shown that iron improves intellectual performance $(16,17,26)$. The fact that the effect of iron on the psychomotor performance of iron-deficient individuals is more easily demonstrated in adolescents than in young children may be due to neuropsychological tests being more difficult to interpret in the younger age group.

Although the causal relationship has not been conclusively proven, from a public health perspective, neurological impairment must be regarded as the most worrying manifestation of ID in young children.

\section{Causes of iron-deficiency anaemia}

There are two principal causes of IDA in young children: increased iron losses through bleeding (haemorrhagic IDA), and insufficient dietary iron intake (nutritional IDA). Sometimes, IDA can be caused by a combination of these two mechanisms.

\section{Haemorrhagic iron-deficiency anaemia}

Blood loss is the most common cause of IDA world-wide (27). The reason is almost always gastrointestinal bleeding, which is most often occult and can only be detected by a test for blood in stools. Common causes of chronic, occult gastrointestinal haemorrhage in early childhood are intestinal infection (e.g. hookworm, Giardia), food intolerance (e.g. cow's milk allergy) and malformations (e.g. Meckel's diverticulum) (27). A more detailed account of causes of haemorrhagic IDA is beyond the scope of this review. In some cases of food intolerance (including coeliac disease) and other inflammatory states of the enteric mucosa, general malabsorption results. In these cases, ID may be caused by a combination of blood loss and poor iron absorption.

\section{Nutritional iron-deficiency anaemia}

Factors determining the risk for young children of developing nutritional IDA are birth weight, maternal and obstetrical factors, and diet.

\section{Birth weight}

It has been estimated that the term newborn has a total body iron content averaging about $75 \mathrm{mg}$ $\mathrm{kg}^{-1}$ body weight (28), which can be compared with $55 \mathrm{mg} \mathrm{kg}^{-1}$ for an adult. Although placental iron transport is negligible during the first two trimesters, it rises progressively to $4 \mathrm{mg}$ daily towards the end of the third trimester (11). Consequently, both birth weight and gestational age are major determinants of the total body iron content at birth, although interindividual variation is considerable.

\section{Maternal and obstetrical factors}

The amount of circulating $\mathrm{Hb}$ iron is a function of the concentration of $\mathrm{Hb}$ and the blood volume. The average $\mathrm{Hb}$ concentration of cord blood from normal term infants is $170 \mathrm{~g} \mathrm{l}^{-1}$, with a range from 135 to $210 \mathrm{~g}^{-1}(11)$. The average blood volume at birth is about $85 \mathrm{ml} \mathrm{kg}^{-1}$; thus depending mostly on birth weight, but to some extent also on the timing of umbilical cord clamping (29). Thus, for infants with similar birth weights, individual variations in $\mathrm{Hb}$ and blood volume at birth are major causes of differences in body iron content.

Iron supplements are commonly recommended for pregnant women but many studies have failed to show any correlation between maternal $\mathrm{Hb}$ and cord blood $\mathrm{Hb}$. It has therefore generally been assumed that the iron status of the foetus, and subsequently the infant, is rather independent of maternal iron status during pregnancy (11). However, a direct effect of maternal iron status on infant iron stores has recently been suggested, and further studies are needed to investigate this possibility (27, $30)$. 


\section{Diet}

Cow's milk. In the authors' clinical experience in Sweden, most cases of severe nutritional IDA in infancy and early childhood occur when parents do not follow the nutritional advice routinely given by health-care centres. This may be due to language problems, cultural differences or economical problems. Affected infants are typically 6-18 months old, have difficulties in the transition to a solid diet after discontinuation of breast-feeding, and often have been fed whole cow's milk almost exclusively for several months. In these infants, the high risk for severe IDA is easily explained by the low concentration of iron in cow's milk (about $0.3 \mathrm{mg} \mathrm{1}^{-1}$ ), its poor bioavailability [about 10\% absorbed (31)] and, above all, the lack of other dietary sources of iron.

In some susceptible infants, whole cow's milk induces gastrointestinal bleeding and, in these, the risk for IDA increases when $>500-1000 \mathrm{ml}$ of whole cow's milk is consumed daily (32). The susceptibility to cow's milk-induced gastrointestinal bleeding seems to decrease with age and this condition is rarely seen after 2 years of age. The factor that induces blood loss has not been identified, but several studies have shown that cow's milk formula reduces intestinal bleeding significantly compared with whole cow's milk $(32,33)$.

Exclusive breast-feeding. Human milk has unique properties and most authorities therefore recommend exclusive breast-feeding until about 6 months of age $(34,35)$. However, the concentration of iron in human milk is low $\left(0.2-0.4 \mathrm{mg} \mathrm{1}^{-1}\right)$; this is thought to be partly compensated for by its high bioavailability, which is frequently cited as $50 \%$ (36). However, the fractional absorption of iron from breast milk is highly variable and it was shown recently that it changes with infant age and dietary iron intake (37). Assuming a daily intake of $800 \mathrm{ml}$ breast milk and an absorption of $50 \%$, an exclusively breast-fed 4-month-old infant would absorb $0.12 \mathrm{mg}$ of iron daily. This is approximately sufficient for covering the estimated basal iron losses (20 $\mu \mathrm{g} \mathrm{kg}^{-1}$ per day) (12), but does not allow for net gain of iron. Thus, additional sources of iron are needed after about 4-6 months when neonatal iron stores have been depleted (Fig. 2). This is one of the major reasons why it is recommended to introduce complementary food at 4-6 months of age $(38,39)$. The time at which IDA will develop in exclusively breast-fed infants depends on the size of iron stores at birth. In a Finnish study of 36 exclusively breast-fed infants at 9 months of age, none had IDA (40). The authors' clinical experience is that Swedish infants who are exclusively breast-fed for a prolonged period typically develop IDA at about 12 months of age. However, in populations where maternal and obstetrical factors or low birth weight may compromise infant iron stores at birth, i.e. most developing countries, IDA in is likely to develop soon after the age of 4-6 months in exclusively breast-fed infants (15).

Complementary food and formula. Partial breastfeeding together with complementary food (possibly including formula) is recommended from 4-6 months until $1-2$ years of age $(34,35)$. Partially breast-fed infants who consume unfortified complementary food are at higher risk for IDA than exclusively breast-fed infants (41). One reason for this is likely to be poor bioavailability of iron in the complementary food. Thus, in partially breastfed infants, the composition of the complementary food is crucial for the prevention of IDA. In clinical practice, moderate or severe nutritional IDA is very uncommon in Scandinavian infants and young children on a diversified diet. This is probably due to the use of iron-fortified infant foods in combination with adequate iron stores at birth. However, in some studies, the prevalence of mild IDA has been reported to be high in Swedish infants at 1-2 years of age $(42,43)$. This has prompted a re-evaluation of current diagnostic criteria.

\section{Diagnostic criteria}

From Table 1, it may seem that the diagnosis of ID and IDA should be easy, using the available battery of tests for the clinical evaluation of iron status. Indeed, this is most often the case for severe IDA. In milder cases, however, the interpretation of iron status is more challenging since the resulting combination of normal and abnormal values in many cases does not fit into the theoretical model (Table 1). The reason for this is that each of the iron status variables reflects different aspects of iron metabolism (20). Another problem is that mild or moderate ID, unlike most other pathological conditions, is often totally asymptomatic. It is therefore not surprising that there is no consensus about the laboratory criteria for ID and IDA in adults or children (44).

In the absence of other conditions causing anaemia, IDA is usually defined as a low $\mathrm{Hb}$ 
Table 1. Theoretical changes in iron status variables in iron overload and iron deficiency of increasing severity

\begin{tabular}{|c|c|c|c|c|c|c|}
\hline \multirow[t]{2}{*}{ Compartment } & \multirow[t]{2}{*}{ Variable } & \multirow[t]{2}{*}{ Iron overload } & \multirow[t]{2}{*}{ Mild ID } & \multicolumn{2}{|c|}{ Moderate ID } & Severe ID \\
\hline & & & & No IDA & Mild IDA & Severe IDA \\
\hline \multirow[t]{3}{*}{$\mathrm{BM}$ and $\mathrm{RBC}$} & $\mathrm{Hb}$ & $N$ & $N$ & $N$ & - & -- \\
\hline & $\mathrm{MCV}$ & $N$ & $N$ & $N$ & - & -- \\
\hline & ZPP & $N$ & $N$ & + & ++ & ++ \\
\hline \multirow[t]{3}{*}{ Serum } & $\mathrm{S}-\mathrm{Fe}$ & ++ & $N$ & - & -- & -- \\
\hline & TIBC & -- & $N$ & + & ++ & ++ \\
\hline & TfSat & ++ & $N$ & - & -- & -- \\
\hline Tissues & TfR & $\mathrm{N}$ & $N$ & + & ++ & ++ \\
\hline Stores & Ferritin & ++ & - & -- & -- & -- \\
\hline
\end{tabular}

ID: iron deficiency; IDA: iron deficiency anaemia; BM: bone marrow; RBC: red blood cells; Hb: haemoglobin; MCV: erythrocyte mean cell volume; ZPP: zinc protoporphyrin; S-Fe: serum iron; TIBC: total iron binding capacity in serum (transferrin); TfSat: transferrin saturation with iron (calculated from S-Fe and TIBC); TfR: soluble transferrin receptors; N: normal or almost normal; $-/--$ : lower/much lower than normal; $+/++$ : higher/much higher than normal.

together with other indicators of ID such as either low serum ferritin (45) or a combination of multiple criteria (i.e. abnormal values for any two out of three variables of iron status) (46). Even though the multiple criteria model is most commonly used, there is no consensus on whether to use single or multiple criteria, or which iron status variables to use in the multiple criteria model $(16,44)$.

\section{Postnatal changes in iron metabolism}

The interpretation of iron status in infants and young children is complicated by the dramatic physiological changes seen in most measures of iron status during this period of life.

\section{Changes in haemoglobin and erythrocyte mean cell volume}

Directly after birth, there is a sudden increase in tissue oxygen tension, which is reflected by a marked decrease in plasma erythropoietin, in turn leading to a virtual cessation of erythropoiesis and $\mathrm{Hb}$ synthesis during the first $6-8$ weeks of life $(11,29)$. Coincident with the ensuing decline in $\mathrm{Hb}$ is a shift of iron from the circulating $\mathrm{Hb}$ mass to storage sites. It is not until the $\mathrm{Hb}$ concentration falls from the umbilical cord level of $170 \mathrm{~g} 1^{-1}$ to about $120 \mathrm{~g}^{-1}$ that erythropoiesis resumes.

After the rapid decrease in $\mathrm{Hb}$ during the first 2-3 months of life, there is a slow decrease until a nadir is reached at about $8-18$ months of age, when mean $\mathrm{Hb}$ is usually $110-120 \mathrm{~g}^{-1}$. After 2 years of age, mean $\mathrm{Hb}$ slowly increases to $135-140 \mathrm{~g} \mathrm{l}^{-1}$ at 12 years of age $(47,48)$.

Foetal and neonatal erythrocytes are considerably larger than those of older children and adults. The erythrocyte mean cell volume (MCV) is on the average $135 \mathrm{fl}$ at $24-25$ weeks of gestation and 119 $\mathrm{fl}$ at term, reaches a nadir of $72-77 \mathrm{fl}$ at about $6-18$ months of age and thereafter steadily increases to $85-90 \mathrm{fl}$ in adults $(29,47-49)$.

From the above it can be concluded that infants between 6 months and 2 years of age have lower $\mathrm{Hb}$ and lower MCV than at any other age. In unselected populations of seemingly well-nourished infants in this age interval, many studies have reported a high prevalence of mild anaemia $(42,47,50,51)$. Large doses of intramuscular iron given to 9-month-old well-nourished infants (three doses over 1 month, totalling $250 \mathrm{mg}$ of iron), resulted in slightly higher mean $\mathrm{Hb}$ at 12 months of age (123 g $1^{-1}$ compared with $116 \mathrm{~g}^{-1}$ in controls) but no significant difference in mean MCV (79 $\mathrm{fl}$ in treated compared with $77 \mathrm{fl}$ in controls) (52). This suggests that part of this "anaemia of late infancy" is caused by ID, but a sizeable proportion of the low $\mathrm{Hb}$, and especially the low MCV, at 6-24 months of age probably reflects normal physiological changes in the developing infant.

\section{Changes in other iron status variables}

Ferritin. Mean serum ferritin is high at birth in term infants $\left(100-200 \mu \mathrm{g}^{-1}\right)$ and increases further to $200-400 \mu \mathrm{g} 1^{-1}$ during the first weeks of life. After erythropoiesis resumes there is a progressive decline in serum ferritin to about $30 \mu \mathrm{g}^{-1}$ at 1 year of age (53). Since these changes parallel the theoretical early increase and later decrease in body iron stores (see above), ferritin is considered a valid measure of iron stores in infants, even though it should be noted that this has never been validated by other methods (11). 
Zinc protoporphyrin. Zinc protoporphyrin (ZPP) is formed when zinc, instead of iron, is incorporated into protoporphyrin during the final step of haem biosynthesis (54). This occurs more often in states of iron-deficient erythropoiesis, and the ratio between ZPP and haem is used clinically to detect states of preanaemic iron depletion (55). As yet, this indicator has not been characterized and used extensively in young children (20). ZPP decreases from 4 to 9 months of age in healthy, breast-fed infants (15).

Transferrin receptors. Soluble transferrin receptor (TfR), a novel indicator of iron status, can be demonstrated in serum and has been suggested to correlate well with cellular iron needs (56). Unlike serum ferritin, TfR is not affected by inflammation or infection (57). However, there is currently no international standard for TfR and commercially available assays vary with regard to reference values (58). Several studies have confirmed that mean levels of soluble TfR are considerably higher in infants than in adults $(15,59)$. The reason for this is not yet known, even though one could speculate that it might be due to a large proportion of rapidly dividing cells in the growing infant. Compared with many other indices of iron status, TfR concentrations are relatively stable during the first year of life (10).

Other indicators. For serum iron and transferrin saturation, there is a considerable diurnal variation with high values in the morning and after meals. In addition, there is considerable overlap in these indices between normal and iron-deficient subjects, which diminishes their usefulness in diagnosing ID (20).

\section{Definition of iron-deficiency anaemia in infants}

Commonly used cut-off values for $\mathrm{Hb}$ and other iron status variables in infants are often based on data extrapolated from older children, and have been challenged $(50,51)$. New cut-off values have recently been suggested based on iron-replete, breast-fed, unsupplemented infants at 4-9 months of age (Table 2) (10).

Notably, the cut-off value for $\mathrm{Hb}$ to define anaemia at 9 months was $100 \mathrm{~g}^{-1}$ rather than 110 $\mathrm{g}^{-1}(60)$ and the cut-off for ferritin at 9 months was $5 \mu \mathrm{g} 1^{-1}$ rather than $12 \mu \mathrm{g}^{-1}$ (60). The authors further suggest an alternative multiple criteria definition for IDA in this age interval: low $\mathrm{Hb}$ in combination with one of the following: high
Table 2. Suggested 2 standard deviation cut-off values for iron status variables at 4, 6 and 9 months of age, based on iron-replete, breast-fed infants

\begin{tabular}{lrrc}
\hline & $4 \mathrm{mo}$ & $6 \mathrm{mo}$ & $9 \mathrm{mo}$ \\
\hline $\mathrm{Hb}\left(\mathrm{g} \mathrm{I}^{-1}\right)$ & $<105$ & $<105$ & $<100$ \\
$\mathrm{MCV}(\mathrm{fl})^{\mathrm{a}}$ & $<73$ & $<7 \mid$ & $<7 \mid$ \\
$\mathrm{ZPP}\left(\left.\mu \mathrm{mol} \mathrm{mol}\right|^{-1}\right.$ haem $)$ & $>75$ & $>75$ & $>90$ \\
Ferritin $\left(\mu \mathrm{I} \mathrm{I}^{-1}\right)$ & $<20$ & $<9$ & $<5$ \\
$\operatorname{TfR}(\mathrm{mg} \mathrm{|-1})$ & $>11$ & $>11$ & $>11$ \\
\hline
\end{tabular}

$\mathrm{Hb}$ : haemoglobin; MCV: erythrocyte mean cell volume; ZPP: zinc protoporphyrin; TfR: soluble transferrin receptors.

a Based on Swedish infants.

ZPP, low ferritin or high TfR, based on the 2 SD cut-off values from Table 2 (10).

\section{Haemoglobin response to iron}

It has recently been shown that $\mathrm{Hb}$ increases as a response to iron supplementation from 4 to 6 months of age, independent of initial iron status, suggesting that the $\mathrm{Hb}$ response to iron is not useful as a criterion of IDA in infants below 6 months of age, at least not in infants without severe anaemia (10). This latter observation is important and should lead to a more cautious interpretation of $\mathrm{Hb}$ outcome in any study in which iron supplementation is given to infants below 6 months of age.

\section{Infant gender}

It is well known that there are differences in iron status between males and females in adolescence and adulthood (61), but it is commonly assumed that there is no difference in iron status between boys and girls before puberty.

One study found significant gender differences in $\mathrm{Hb}, \mathrm{MCV}, \mathrm{ZPP}$, ferritin and TfR at 4, 6 and 9 months, seemingly suggesting a higher prevalence of ID in boys. At 9 months, boys had an approximately 10 -fold increased risk for being diagnosed with IDA. Significant gender differences remained when controlling for growth and diet. The gender differences in some variables (MCV, ZPP and ferritin) may be due to genetic or hormonal factors, whereas the differences in some other variables $(\mathrm{Hb}$ and TfR) probably reflect a truly increased risk of ID in boys (Domellöf et al. submitted).

\section{Prevention}

\section{Dietary recommendations}

Exclusive breast-feeding is recommended until 4-6 months of age $(34,38)$. At this age, complementary 
foods should be introduced, but breast-feeding should be continued until at least 1 year of age (34, 38). Recently, the World Health Assembly recommended exclusive breast-feeding until 6 months and partial breast-feeding until 2 years of age (35).

The complementary food should preferably be varied. Iron-rich food, e.g. meat, should be included, adequate vitamin $C$ intake should be ensured and known inhibitors of iron absorption (high-fibre cereals, tea, coffee) should be avoided. Furthermore, whole cow's milk should be avoided until the age of $10-12$ months $(39,62)$ and unfortified infant formula should not be used at all.

\section{Iron fortification}

Since even a perfectly diversified and balanced unfortified diet does not cover the estimated iron needs at 6-12 months of age (14), iron fortification of common infant foods is practised in many countries.

Formula before 6 months. It has long been recognized that iron fortification of infant formula significantly reduces the risk for IDA (7), even though the optimal level of iron fortification still remains to be determined (63). The concentrations of iron in different iron-fortified infant formulae are commonly $10-12 \mathrm{mg}^{-1}$ in the USA and $4-7 \mathrm{mg}^{-1}$ in Europe (64). An even lower level of fortification may suffice: in healthy, term Swedish infants, no difference was found in iron status (including $\mathrm{Hb}$ ) at 6 months between those exclusively breast-fed and those exclusively fed formula with 2,4 or $7 \mathrm{mg}$ iron $1^{-1}$ from 1 to 6 months of age $(65$, Hernell at al, submitted). However, to the authors' knowledge, there have been no studies investigating whether the concentration of iron in infant formula, given from 0 to 6 months of life, has any effect on iron status at 12-24 months of life.

Formula after 6 months. After 6 months of age, infant formula or follow-on formula normally should be combined with other foods. The optimal concentration of iron in follow-on formula to prevent IDA at 6-24 months of age depends on the individual iron needs of the infant as well as on the quantity of formula consumed (ranging from $<1 \%$ to $100 \%$ of the diet in different individuals during different periods). However, it also depends on the total intake of bioavailable iron from all other dietary sources from 0 to 24 months of age.

Assuming a daily intake of $500 \mathrm{ml}$ follow-on formula with an iron content of $10 \mathrm{mg}^{-1}$ and a bioavailability of $10 \%$, the iron intake from formula would be $5 \mathrm{mg} \mathrm{day}^{-1}$, which is approximately $60 \%$ of the estimated daily requirement (12) or even more if the iron requirements of healthy, term Scandinavian infants are lower than previously believed (as suggested above). The remaining iron will in this case have to be provided from other iron-rich foods (e.g. meat products or iron-fortified foods).

Other foods. Formula has been most extensively studied, but other iron-fortified infant foods (e.g. cereals) have also been found to be effective in preventing IDA (66).

\section{Iron supplementation}

Low birth-weight (LBW, $<2500 \mathrm{~g}$ ) infants have low iron stores at birth and a rapid postnatal growth rate, theoretically leading to a depletion of iron stores within 2-3 months of age (12). Different authorities therefore recommend iron supplementation (at least $2 \mathrm{mg} \mathrm{kg}^{-1}$ body weight daily) of all LBW infants starting at 2-8 weeks of age and continuing to $1-2$ years of age $(60,67,68)$. However, local recommendations vary widely (69), and there is a need for randomized studies addressing long-term psychomotor outcome to determine the optimal dose and duration of iron supplementation to LBW infants.

Iron drops at a dose corresponding to $1-2 \mathrm{mg} \mathrm{Fe}$ $\mathrm{kg}^{-1}$ per day have been recommended for term infants who are exclusively breast-fed between 4 and 6 months (70) and for infants after 6 months of age if they do not consume adequate amounts of ironfortified foods (e.g. at least $400 \mathrm{ml}$ of iron-fortified formula daily) (71-73). Furthermore, in developing countries, a separate iron supplement (ferrous sulfate mixture, $1-2 \mathrm{mg} \mathrm{kg}^{-1}$ daily) given to all infants is a low-cost alternative to food fortification (15). Iron supplementation of term, breast-fed infants from 4 or 6 months to at least 9 months of age can prevent IDA in a socioeconomically disadvantaged population with a high prevalence of IDA (15).

\section{Safety aspects}

Iron poisoning. An accidental overdose of iron may lead to acute iron poisoning, which is potentially lethal (74). Iron supplements should therefore always be kept out of reach of children.

Infections. Iron is a known trophic factor for several pathogenic bacteria and there has also been concern that iron supplementation of breast-fed infants may saturate human milk lactoferrin, thus 
diminishing its anti-infective properties (75). Parenteral iron therapy has been associated with the exacerbation of malaria and neonatal sepsis (76). For these reasons, it has been suggested that iron fortification and supplementation may increase the incidence of gastroenteritis and other infections in infants. However, several studies have failed to confirm this theory for iron-fortified formula. One study even showed that iron fortification provided a small, but significant degree of protection against diarrhoea (77).

Growth. Several studies have addressed the issue of whether iron supplementation affects growth, but the results have been contradictory. Iron supplementation to anaemic (24) or malnourished children $(78,79)$ resulted in improved growth; in the latter case possibly due to reduced morbidity. Some studies have shown no effect of iron on growth $(22,80,81)$, whereas two studies has shown a negative effect on body growth when iron supplements were given to iron-sufficient infants (82, 83). Iron supplementation given to infants at a dose of $1 \mathrm{mg} \mathrm{kg}^{-1}$ per day between 4 and 9 months of age had a negative effect on length gain and head circumference growth. This effect was more pronounced in Swedish than in Honduran infants, and it was more pronounced in infants with initial $\mathrm{Hb}>110 \mathrm{~g} \mathrm{l}^{-1}$, suggesting that ironsufficient infants are more susceptible to this complication. The mechanism for this effect is unknown (10).

Mineral absorption. There has been concern that iron supplements or iron fortification at the levels currently used may compete with other divalent ions, e.g. zinc and copper, and thus decrease the absorption of these minerals. Studies have suggested that this may be the case for copper $(66,84)$ but not for zinc (85). The present authors found no effect of iron supplementation on plasma zinc levels in infants (unpublished data), but it should be noted that plasma zinc is not an optimal indicator of zinc status.

Long-term effects. Considering the possible longterm effects of iron overload (e.g. cardiovascular disease (86) and cancer (87)), short-term iron supplementation or fortification in infancy at currently recommended levels is unlikely to have any major influence on iron status in adulthood.
Iron supplements. For several reasons, a cautious approach is warranted with regard to routine iron supplementation (e.g. iron drops) during infancy. First, iron-replete infants at 6-9 months of age were unable effectively to down-regulate iron absorption (37). Secondly, a seemingly unregulated $\mathrm{Hb}$ response to iron was found in iron-replete infants at 4-6 months (15). Thirdly, a retardation of longitudinal growth and head growth was found in iron-supplemented Swedish infants (83).

In poor regions with a high prevalence of IDA, the advantages of iron supplementation are likely to outweigh these possible disadvantages. However, in more affluent regions, and in those with a wide range in economic and nutritional status, universal iron supplementation of breast-fed infants may cause unwanted effects in a significant proportion of the population. Although targeting is costly and sometimes impractical, it may be a safer option in such situations.

National screening programmes are not feasible because of high costs and a lack of sensitive and specific biochemical markers for ID, but smaller programmes should perhaps be set up in areas containing a high number of at-risk children (e.g. inner cities with large numbers of socioeconomically disadvantaged families).

Iron-fortified foods. No study has shown any negative effects of iron fortification of infant foods at current levels. Iron fortification can therefore still be recommended to populations with a large proportion of iron-replete infants and young children.

\section{Perspectives}

Further studies are needed to assess more accurately the total body iron in newborns and infants at different risk for IDA. Novel techniques have to be developed to measure total body iron accurately and non-invasively, e.g. improved magnetic resonance imaging or magnetic susceptibility measurement $(88,89)$. This would also be useful to validate ferritin and other variables as measures of iron status in infants.

Ultimately, determination of iron requirements should not be based on laboratory values or theoretical calculations. Instead, recommendations should be based on the minimal iron intake that prevents physiological consequences of ID. More research is therefore needed to clarify the relation between dietary iron intake in infancy, iron status and long-term physiological outcomes such as neu- 
rological development. Since IDA is a global public health problem and since the first years of life are a crucial period for growth and development of the central nervous system, this issue deserves high priority.

\section{References}

1. DeMaeyer E, Adiels-Tegman M: The prevalence of anaemia in the world. World Health Stat Q 1985;38:302-16.

2. Fairweather-Tait SJ: Iron deficiency anaemia: epidemiology, complications, diagnosis and management. Int Sem Paediatr Gastroenterol Nutr 1996;5:3-7.

3. Zuelzer WW. Pediatric hematology in historical perspective. In: Nathan DG, Orkin SH, eds. Nathan and Oski's hematology of infancy and childhood. Philadelphia, PA: WB Saunders, 1998; 3-16.

4. Barness LA: History of infant feeding practices. Am J Clin Nutr 1987;46:168-70.

5. Mackay HM: Anaemia in infancy: its prevalence and prevention. Arch Dis Child 1928;3:117-47.

6. Haughton JG: Nutritional anemia of infancy and childhood. Am J Public Health 1963;53:1121-6.

7. Marsh A, Long H, Stierwalt RN: Comparative hematologic response to iron fortification of a milk formula for infants. Pediatrics 1959;24:404-12.

8. Andelman MB, Sered BR: Utilization of dietary iron by term infants. A study of 1,048 infants from a low socioeconomic population. Am $\mathbf{J}$ Dis Child 1966;111:45-55.

9. Yip R, Walsh KM, Goldfarb MG, Binkin NJ: Declining prevalence of anemia in childhood in a middle-class setting: a pediatric success story? Pediatrics 1987; $80: 330-4$.

10. Domellöf M. Iron requirements of term, breast-fed infants: a study in Sweden and Honduras. Thesis, Umeå University, Umeå: 2001.

11. Lukens JN. Iron metabolism and iron deficiency. In: Miller DR, Baenher RL, eds. Blood diseases of infancy and childhood. St. Louis: Mosby, 1995:193-219.

12. Oski FA: Iron deficiency in infancy and childhood. $\mathrm{N}$ Engl J Med 1993;329:190-3.

13. Dallman PR. Changing iron needs from birth through adolescence. In: Fomon SJ, Zlotkin S, eds. Nutritional anemias. New York: Vevey/Raven Press, 1992; 29-36.

14. World Health Organization (WHO). Complementary feeding of young children in developing countries: a review of current scientific knowledge. Geneva: WHO, 1998.

15. Domellöf M, Cohen RJ, Dewey KG et al: Iron supplementation of breast-fed Honduran and Swedish infants from 4 to 9 months of age. J Pediatr 2001;138:679-87.

16. Grantham-McGregor SM, Ani CC: The role of micronutrients in psychomotor and cognitive development. Br Med Bull 1999;55:511-27.
17. Nokes C, Bosch van den C, Bundy DAP. The effects of iron deficiency and anemia on mental and motor performance, educational achievement and behaviour in children: an annotated bibliography. Washington, DC: International Nutritional Anemia Consultative Group (ICNAG), 1998.

18. Roncagliolo M, Garrido M, Walter T et al: Evidence of altered central nervous system development in infants with iron deficiency anemia at 6 mo: delayed maturation of auditory brainstem responses. Am J Clin Nutr 1998;68:683-90.

19. Yu GS, Steinkirchner TM, Rao GA, Larkin EC: Effect of prenatal iron deficiency on myelination in rat pups. Am J Pathol 1986;125:620-4.

20. Aggett PJ, Agostoni C, Axelsson I, et al. Iron metabolism and needs in early childhood: do we know enough? A commentary by the ESPGHAN Committee on Nutrition. J Pediatr Gastroenterol Nutr 2002 (in press).

21. Idjradinata P, Pollitt E: Reversal of developmental delays in iron-deficient anaemic infants treated with iron. Lancet 1993;341: 1-4.

22. Moffatt ME, Longstaffe S, Besant J, Dureski C: Prevention of iron deficiency and psychomotor decline in high-risk infants through use of iron-fortified infant formula: a randomized clinical trial. $\mathrm{J}$ Pediatr 1994; 125:527-34.

23. Williams J, Wolff A, Daly A et al: Iron supplemented formula milk related to reduction in psychomotor decline in infants from inner city areas: randomised study. Br Med J 1999;318:693-7.

24. Aukett MA, Parks YA, Scott PH, Wharton BA: Treatment with iron increases weight gain and psychomotor development. Arch Dis Child 1986;61:849-57.

25. Walter T, deAndraca I, Chadud P, Perales CG: Iron deficiency anemia: adverse effects on infant psychomotor development. Pediatrics 1989;84:7-17.

26. Bruner AB, Joffe A, Duggan AK et al: Randomised study of cognitive effects of iron supplementation in non-anaemic iron-deficient adolescent girls. Lancet 1996;348:992-6.

27. Andrews NC, Bridges KR. Disorders of iron metabolism and sideroblastic anemia. In: Nathan DG, Orkin SH, eds. Nathan and Oski's hematology of infancy and childhood. Philadelphia, PA: WB Saunders, 1998; 423-61.

28. Widdowson EM, Spray CM: Chemical development in utero. Arch Dis Child 1951;26:205-14.

29. Brugnara C, Platt OP. The neonatal erythrocyte and its disorders. In: Nathan DG, Orkin SH, eds. Nathan and Oski's hematology of infancy and childhood. Philadelphia, PA: WB Saunders, 1998; 19-52.

30. Allen LH. Anemia and iron deficiency: effects on pregnancy outcome. Am J Clin Nutr 2000; 71 (5 Suppl): $1280-4 \mathrm{~S}$.

31. Lönnerdal B: Effects of milk and milk components on calcium, magnesium, and trace element absorption during infancy. Physiol Rev 1997;77:643-69.

32. Wilson JF, Lahey ME, Heiner DC: Studies on iron metabolism. V. Further observations on cow's milk-in- 
duced gastrointestinal bleeding in infants with iron-deficiency anemia. J Pediatr 1974;84:335-44.

33. Ziegler EE, Jiang T, Romero E et al: Cow's milk and intestinal blood loss in late infancy. $\mathrm{J}$ Pediatr 1999; $135: 720-6$.

34. American Academy of Pediatrics. Work Group on Breastfeeding. Breastfeeding and the use of human milk. Pediatrics 1997;100:1035-9.

35. World Health Assembly (WHA). Infant and young child nutrition. Resolution WHA 5422001.

36. Saarinen UM, Siimes MA, Dallman PR: Iron absorption in infants: high bioavailability of breast milk iron as indicated by the extrinsic tag method of iron absorption and by the concentration of serum ferritin. $\mathbf{J}$ Pediatr 1977;91:36-9.

37. Domellöf M, Lönnerdal B, Abrams SA, Hernell O. Iron absorption in breast-fed infants: Effect of age, iron status, iron supplements and complementary foods. Am J Clin Nutr 2002 (in press).

38. Michaelsen KF, Weaver L, Branca F, Robertson A. Feeding and nutrition of infants and young children. Guidelines for the WHO European Region. Copenhagen: World Health Organization, 2000.

39. Livsmedelsverket (Swedish Food Administration). Mat för spädbarn: råd och inspiration till föräldrar (Food for infants: advice and inspiration to parents). Livsmedelsverket, Uppsala: 1999.

40. Siimes MA, Salmenperä L, Perheentupa J: Exclusive breast-feeding for 9 months: risk of iron deficiency. J Pediatr 1984;104:196-9.

41. Pisacane A, De VB, Valiante A et al: Iron status in breast-fed infants. J Pediatr 1995;127:429-31.

42. Persson LÅ, Lundström M, Lönnerdal B, Hernell O: Are weaning foods causing impaired iron and zinc status in 1-year-old Swedish infants? A cohort study. Acta Paediatr 1998;87:61 8-22.

43. Bramhagen A-C, Axelsson I: Iron status of children in southern Sweden: effects of cow's milk and follow-on formula. Acta Paediatr 1999;88:1333-7.

44. Worwood M: The laboratory assessment of iron status - an update. Clin Chim Acta 1997;259:3-23.

45. Hallberg L, Bengtsson C, Lapidus L et al: Screening for iron deficiency: an analysis based on bone-marrow examinations and serum ferritin determinations in a population sample of women. Br J Haematol 1993; 85:787-98.

46. Cook JD, Finch CA, Smith NJ: Evaluation of the iron status of a population. Blood 1976;48:449-55.

47. Guest GM, Brown EW, Wing M: Erythrocytes and hemoglobin of the blood in infancy and in childhood: II. Variability in number, size and hemoglobin content of the erythrocytes during the first five years of life. Am J Dis Child 1938;56:529-49.

48. Dallman PR, Siimes MA: Percentile curves for hemoglobin and red cell volume in infancy and childhood. J Pediatr 1979;94:26-31.

49. Saarinen UM, Siimes MA: Developmental changes in red blood cell counts and indices of infants after exclusion of iron deficiency by laboratory criteria and continuous iron supplementation. J Pediatr 1978;92:412-6.
50. Emond AM, Hawkins N, Pennock C, Golding J: Haemoglobin and ferritin concentrations in infants at 8 months of age. Arch Dis Child 1996;74:36-9.

51. Sherriff A, Emond A, Hawkins N, Golding J: Haemoglobin and ferritin concentrations in children aged 12 and 18 months. ALSPAC Children in Focus Study Team. Arch Dis Child 1999;80:153-7.

52. Sturgeon P. Iron metabolism: a review with special consideration of iron requirements during normal infancy. Pediatrics 1956;18:267-98.

53. Saarinen UM, Siimes MA: Serum ferritin in assessment of iron nutrition in healthy infants. Acta Paediatr Scand 1978;67:745-51.

54. Hastka J, Lasserre JJ, Schwarzbeck A et al: Laboratory tests of iron status: correlation or common sense? Clin Chem 1996;42:718-24.

55. Rettmer RL, Carlson TH, Origenes ML et al: Zinc protoporphyrin/heme ratio for diagnosis of preanemic iron deficiency. Pediatrics 1999;104; 37.

56. Cook JD, Baynes RD, Skikne BS: The physiological significance of circulating transferrin receptors. Adv Exp Med Biol 1994;352:119-26.

57. Ferguson BJ, Skikne BS, Simpson KM et al: Serum transferrin receptor distinguishes the anemia of chronic disease from iron deficiency anemia. J Lab Clin Med 1992;119:385-90.

58. Åkesson A, Bjellerup P, Vahter M: Evaluation of kits for measurement of the soluble transferrin receptor. Scand J Clin Lab Invest 1999;59:77-81.

59. Choi JW, Pai SH, Im MW, Kim SK: Change in transferrin receptor concentrations with age. Clin Chem 1999;45:1562-3.

60. World Health Organization (WHO). Iron deficiency anemia: assessment, prevention and control. Geneva: WHO, 2001.

61. Bergstrom E, Hernell O, Lonnerdal B, Persson LA: Sex differences in iron stores of adolescents: what is normal? J Pediatr Gastroenterol Nutr 1995;20: 215-24.

62. American Academy of Pediatrics. Committee on Nutrition. The use of whole cow's milk in infancy. Pediatrics 1992;89:1105-9.

63. American Academy of Pediatrics. Committee on Nutrition. Iron fortification of infant formulas. Pediatrics 1999; 104:119-23.

64. Hernell O, Domellöf M, Lind T. Iron requirements in infant formulas during the first six months of life. In: Räihä NCR, Rubatelli FF, eds. Infant formula: closer to the reference. Philadelphia, PA: Lippincott Williams \& Wilkins, 2002; 71-84.

65. Lönnerdal B, Hernell O: Iron, zinc, copper and selenium status of breast-fed infants and infants fed trace element fortified milk-based infant formula. Acta Paediatr 1994;83:367-73.

66. Walter T, Dallman PR, Pizarro F et al: Effectiveness of iron-fortified infant cereal in prevention of iron deficiency anemia. Pediatrics 1993;91:976-82.

67. ESPGAN Committee on Nutrition of the Preterm Infant. Nutrition and feeding of preterm infants. Acta Paediatr Scand 1987;Suppl 336:1-14. 
68. Canadian Paediatric Society NC: Nutrient needs and feeding of premature infants. Can Med Assoc J 1995; 152:1765-85.

69. Barclay SM, Lloyd DJ, Duffty P, Aggett PJ: Iron supplements for preterm or low birthweight infants. Arch Dis Child 1989;64:1621-2.

70. Institute of Medicine. Iron deficiency anemia: recommended guidelines for the prevention, detection, and management among US children and women of childbearing age. Washington, DC: National Academy Press, 1993.

71. Centers for Disease Control and Prevention (CDC). Recommendations to prevent and control iron deficiency in the United States. MMWR 1998; 47(RR-3): $1-29$.

72. International Nutritional Anemia Consultative Group (INACG), World Health Organization (WHO), United Nations Children's Fund (UNICEF). Guidelines for the use of iron supplements to prevent and treat iron deficiency anemia. Washington, DC: ILSI Press, 1998.

73. Danish National Board of Health and Welfare (Sundhetsstyrelsen). (Recommendations for infant nutrition). Copenhagen: Sundhetsstyrelsen, 1998.

74. Centers for Disease Control and Prevention (CDC). Toddler deaths resulting from ingestion of iron supplements - Los Angeles, 1992-1993. MMWR 1993;42: $111-3$.

75. Andersson Y, Lindquist S, Lagerqvist C, Hernell O: Lactoferrin is responsible for the fungistatic effect of human milk. Early Hum Dev 2000;59:95-105.

76. Oppenheimer SJ. Iron and infection: the clinical evidence. Acta Paediatr Scand 1989; Suppl 361: 53-62.

77. Scariati PD, Grummer SL, Fein SB, Yip R: Risk of diarrhea related to iron content of infant formula: lack of evidence to support the use of low-iron formula as a supplement for breastfed infants. Pediatrics 1997;99:E2.

78. Angeles IT, Schultink WJ, Matulessi P et al: Decreased rate of stunting among anemic Indonesian preschool children through iron supplementation. Am J Clin Nutr 1993; 58:339-42.

79. Morais MB, Ferrari AA, Fisberg M: Effect of oral iron therapy on physical growth. Rev Paul Med 1993; 111:439-44.
80. Daly A, MacDonald A, Aukett A et al: Prevention of anaemia in inner city toddlers by an iron supplemented cows' milk formula. Arch Dis Child 1996;75:9-16.

81. Morley R, Abbott R, Fairweather-Tait $\mathrm{S}$ et al: Iron fortified follow on formula from 9 to 18 months improves iron status but not development or growth: a randomised trial. Arch Dis Child 1999; $81: 247-52$.

82. Idjradinata P, Watkins WE, Pollitt E: Adverse effect of iron supplementation on weight gain of iron-replete young children. Lancet 1994;343:1252-4.

83. Dewey KG, Domellöf M, Cohen RJ et al: Effects of iron supplementation on growth and morbidity of breastfed infants: a randomized trial in Sweden and Honduras. FASEB J 2000;14: A509.

84. Haschke F, Ziegler EE, Edwards BB, Fomon SJ: Effect of iron fortification of infant formula on trace mineral absorption. J Pediatr Gastroenterol Nutr 1986;5:76873.

85. Bradley CK, Hillman L, Sherman AR et al: Evaluation of two iron-fortified, milk-based formulas during infancy. Pediatrics 1993;91:908-14.

86. Ascherio A, Willett WC, Rimm EB et al: Dietary iron intake and risk of coronary disease among men. Circulation 1994;89:969-74.

87. Stevens RG, Graubard BI, Micozzi MS et al: Moderate elevation of body iron level and increased risk of cancer occurrence and death. Int J Cancer 1994;56:364-9.

88. Kreeftenberg HG Jr, Mooyaart EL, Huizenga JR, Sluiter WJ. Quantification of liver iron concentration with magnetic resonance imaging by combining T1-, T2-weighted spin echo sequences and a gradient echo sequence. Neth J Med 2000;56:133-7.

89. Brittenham GM, Farrell DE, Harris JW et al: Magnetic-susceptibility measurement of human iron stores. N Engl J Med 1982;307:167 1-5.

Magnus Domellöf M.D., Ph.D.

Department of Clinical Sciences, Pediatrics, Umeå University, SE-90I 85 Umeå, Sweden.

E-mail: magnus.domellof@pediatri.umu.se 